\title{
LA TUTELA CAUTELAR AMBIENTAL EN ESPAÑA Y CHILE: UN APUNTE COMPARATIVO
}

\section{ENVIRONMENTAL PRELIMINARY INJUNCTION IN SPAIN AND CHILE: A COMPARATIVE NOTE}

\begin{tabular}{|c|c|}
\hline \multicolumn{2}{|c|}{ ARTÍCULO INÉDITO DE INVESTIGACIÓN } \\
\hline CÓMO CITAR ESTE ARTÍCULO (CHICAGO) & $\begin{array}{l}\text { Valencia Martín, Germán. "La tutela } \\
\text { cautelar ambiental en España y Chile: } \\
\text { Un apunte comparativo". Revista de } \\
\text { Derecho Aplicado LLM UC } 6 \text { (2020). } \\
\text { doi: 10.7764/rda.o.6.I8529. }\end{array}$ \\
\hline REVISTA DE DERECHO APLICADO LLM UC & $\begin{array}{l}\text { Número } 6 \\
\text { Diciembre } 2020 \\
\text { ISSN: } 245^{2-4344}\end{array}$ \\
\hline & $\begin{array}{l}\text { Recepción: } 3 \text { de agosto, } 2020 \\
\text { Aceptación: } 28 \text { de septiembre, } 2020\end{array}$ \\
\hline
\end{tabular}




\section{Resumen}

En este trabajo se compara el régimen de medidas cautelares que aplican los tribunales ambientales chilenos en los asuntos de su competencia con el de los procesos o procedimientos administrativos españoles equivalentes. Se trata en ambos casos de sistemas predominantemente casuísticos, pero con diferentes acentos. Por lo demás, la corta duración de los procesos ante los tribunales ambientales chilenos resta dramatismo a las decisiones cautelares, a diferencia de lo que a menudo ocurre en el contenciosoadministrativo español.

Palabras clave: Tribunales ambientales chilenos, medidas cautelares, reclamaciones de ilegalidad, demandas de reparación por daño ambiental, contencioso-administrativo español.

\section{Abstract}

This paper compares the regime of precautionary measures applied by the Chilean environmental courts in matters within its competence with that of equivalent Spanish administrative processes or procedures. In both cases they are predominantly casuistic systems, but with different accents. Furthermore, the short duration of the proceedings before the Chilean environmental courts reduces the drama of the precautionary decisions, unlike what often happens in the Spanish administrative litigation.

Keywords: Chilean environmental courts, precautionary measures, claims of illegality, claims for repair of environmental damage, Spanish administrative litigation. 


\section{Germán Valencia Martín}

Universidad de Alicante

Alicante, España

german.valencia@ua.es

Universidad de Alicante

Alicante, Spain

german.valencia@ua.es
Germán Valencia Martín es licenciado y doctor en Derecho por la Universidad de Alicante, España. Es profesor titular de Derecho Administrativo de la Universidad de Alicante, donde es también coordinador del Máster Universitario en Derecho Ambiental y de la Sostenibilidad (MADAS) y director del Grupo de Investigación en Derecho Ambiental. Fue letrado del Tribunal Constitucional en régimen de adscripción temporal (1995-1998). Es vicepresidente de la Asociación de Derecho Ambiental Español (ADAME) y director de la Revista Aranzadi de Derecho Ambiental.

Germán Valencia Martín is a graduate and doctor in Law from the University of Alicante, Spain. He is a tenured professor of Administrative Law at the University of Alicante, where he is also coordinator of the University Master's Degree in Environmental and Sustainability Law (MADAS) and director of the Research Group in Environmental Law. He was a lawyer for the Constitutional Court on a temporary basis (1995-1998). He is vice president of the Association of Spanish Environmental Law (ADAME) and director of the Aranzadi Environmental Law Review. 


\section{INTRODUCCIÓN}

Las medidas cautelares o provisionales son una institución universalmente conocida y con un significado en esencia análogo en todos los ordenamientos jurídicos ${ }^{1}$. Sin pretensiones de pureza doctrinal, se entiende por tales las medidas que se toman dentro de un proceso o de un procedimiento administrativo, a veces incluso antes de su inicio, con el fin de evitar que durante su transcurso se produzcan situaciones que puedan comprometer su correcto desarrollo o la efectividad de la resolución que se adopte. A la vista de estas funciones, en el ámbito procesal la adopción de medidas cautelares, aun cuando no se encuentre constitucionalizada en forma expresa, se considera de manera razonable una manifestación más del derecho fundamental a la tutela judicial efectiva (artículo 24.1 de la Constitución española) ${ }^{2}$.

Partiendo de ese denominador común, la regulación de este tipo de medidas puede variar en función de las características propias del procedimiento en el que se inscriben, según se trate, en primer lugar, de un proceso o de un procedimiento administrativo; y, en segundo lugar, de un proceso de un orden jurisdiccional u otro (civil, penal, etcétera) o de un procedimiento administrativo de una u otra naturaleza (sancionador, de reparación de daños, etcétera).

Por eso, al comparar - como aquí nos proponemos-dos ordenamientos jurídicos distintos: el español y el chileno, importa establecer con claridad desde el principio los términos de comparación pertinentes; esto es, dado el origen del trabajo, las equivalencias en el ordenamiento español de los asuntos de que conocen los tribunales ambientales chilenos.

\section{EQUIVALENCIAS}

Como es sabido, no existe en el derecho español una jurisdicción especializada ni tan siquiera un sistema especial de recursos administrativos en materia ambiental, como sin embargo empieza a ser cada vez más frecuente en el panorama comparado ${ }^{3}$.

1 En el derecho español se suele emplear el término cautelares para las adoptadas en sede judicial y provisionales para las que se toman en vía administrativa.

2 En conexión con el derecho al cumplimiento de las sentencias en sus propios términos, tampoco expresamente constitucionalizado, pero derivado del derecho a la tutela judicial efectiva. Por todas, las sentencias del Tribunal Constitucional español I/4/1992, del io de febrero (fundamento jurídico 7) y 238/1992, del 17 de diciembre (fundamento jurídico 3 ). Véase al respecto, entre otros, el espléndido trabajo de Carmen Chinchilla Marín, "El derecho a la tutela cautelar como garantía de la efectividad de las resoluciones judiciales”, Revista de Administración Pú-

Véase al respecto, entre otros, George Pring y Catherine Pring, Environmental Courts \& Tribunals: A Guide for Policy Makers (Nairobi: UNEP, 20I6). 
Los Tribunales Ambientales chilenos, que se inscriben en esa tendencia y cuya entrada en funcionamiento se remonta al año $2012^{4}$, podrían ser calificados desde la perspectiva española como "tribunales especiales", en la medida en que se trata de órganos que ejercen funciones propiamente jurisdiccionales sin estar integrados dentro del Poder Judicial ${ }^{5}$, pero sin formar parte tampoco de la Administración, lo que descarta su calificación como "administraciones independientes" y sobre todo desde luego como "jurisdicción especial”.

Los tribunales ambientales chilenos conocen de tres clases de asuntos, según su agrupación a efectos estadísticos, que de mayor a menor importancia cuantitativa son los siguientes ${ }^{7}$ i) reclamaciones de ilegalidad, ii) demandas de reparación por daño ambiental y iii) solicitudes de la Superintendencia de Medio Ambiente (SMA) ${ }^{8}$.

Las reclamaciones de ilegalidad consisten en la impugnación de actos administrativos de autorización o denegación de proyectos sometidos a evaluación de impacto ambiental, así como de imposición de sanciones administrativas - o archivo de denuncias- por motivos ambientales ${ }^{9}$. Este tipo de procesos se corresponden con los seguidos en España ante los tribunales de lo contencioso-administrativo en caso de impugnación de actos de la misma naturaleza, por lo que el término de comparación adecuado será, pues, en este caso, el régimen cautelar en el ámbito contencioso-administrativo.

4 Se trata de tres tribunales, creados por la Ley 20.600, del I8 de junio de 20r2, que Crea los Tribunales Ambientales (modificada en último término por la Ley 2r.033, del 5 de septiembre de 2017). El Segundo Tribunal (Santiago), inició su funcionamiento el 28 de diciembre de 20I2; el Tercer Tribunal (Valdivia), el 9 de diciembre de 20I3; y el Primer Tribunal (Antofagasta), en septiembre de 2017 .

5 Aunque sí a la "superintendencia directiva, correccional y económica de la Corte Suprema" (artículo I de la Ley 20.600).

6 Según las categorías utilizadas por José Vicente Gimeno Sendra, Fundamentos del derecho procesal (Madrid: Civitas, I98I). También se califican así por su propia ley de creación, la Ley 20.600, artículo I, “Órganos jurisdiccionales especiales”. Calificación no exenta de algunos problemas prácticos, como acredita el espléndido trabajo de Jorge Roberto Retamal Valenzuela, "El ius imperium de los tribunales ambientales en Chile", Revista Derecho del Estado 44 (20I9): $257 \mathrm{y}$ ss.

7 Información disponible en el sitio web del Tercer Tribunal Ambiental de Chile, https://www.

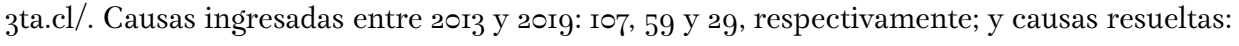
92,37 y 29 , respectivamente.

8 Obviamente, estas competencias se encuentran formuladas de manera más circunstanciada en la propia Ley (artículo I7), que cuenta con ocho apartados y una cláusula residual.

9 Las reclamaciones de ilegalidad cubren seis números del artículo I7. Las más frecuentes, antes referidas, parecen ser las de los números 5 y 3 . Pero también caben, por ejemplo, reclamaciones de ilegalidad frente a reglamentos (artículo i7.I). 
Las demandas de reparación por daño ambiental (artículo 17.2) no tienen equivalente jurisdiccional en el caso español, por tratarse entre nosotros de una materia administrativizada. En efecto, en España la depuración de las posibles responsabilidades por daño ambiental se produce, en primera instancia, a través del procedimiento administrativo independiente previsto por la Ley de Responsabilidad Medioambiental o, en su caso, a través de los procedimientos administrativos sectoriales de carácter sancionador, sin perjuicio de la posibilidad de revisión judicial en vía contencioso-administrativa de una y otra clase de decisiones ${ }^{10}$. El término de comparación para las decisiones cautelares que los tribunales ambientales chilenos toman en esta clase de asuntos - cuantitativa y cualitativamente las más importantes- son, pues, las que en el marco de los mencionados procedimientos pueden tomar en España los órganos administrativos competentes ${ }^{11}$.

Por último, la legislación chilena exige a la Superintendencia de Medio Ambiente, ente institucional dotado de potestad sancionadora, obtener autorización judicial de los Tribunales Ambientales para la adopción o ejecución de ciertos tipos de medidas que suponen una injerencia importante en la libertad o en la propiedad de los ciudadanos, tomadas de manera cautelar o definitiva, es decir, a modo de sanción ${ }^{12}$. Tal exigencia no existe en el derecho español, salvo para la ejecución forzosa de medidas que afecten a la inviolabilidad

10 Véase al respecto, con más detalle, infra, apartado $5 \cdot 3$.

11 Aunque esta es la equivalencia correcta, en algunos aspectos el régimen cautelar aplicado por los tribunales ambientales chilenos en las demandas de reparación por daño ambiental puede resultar, como veremos (infra, apartado 5.I), más afín al de un proceso civil - también al de los procesos civiles españoles - que al de un procedimiento administrativo, pues en estos casos el tribunal resuelve un conflicto entre particulares — no frente a la Administración —, al igual que ocurre en los procesos civiles.

12 La Ley Orgánica de la Superintendencia del Medio Ambiente (Ley 20.417, del I2 de enero de 20ro) prevé estos supuestos, que son: i) sanciones de "clausura temporal o definitiva" y de "revocación de la resolución de calificación ambiental" (artículo 38, letras c y d); ii) medidas provisionales, en el marco de un procedimiento sancionador, de "clausura temporal, parcial o total, de las instalaciones", "detención del funcionamiento de las instalaciones" y "suspensión temporal de la resolución de calificación ambiental" (artículo 48, párrafo primero, letras c, d y e); y iii) medidas también provisionales, pero independientes en principio de un procedimiento sancionador, de suspensión transitoria de las autorizaciones de funcionamiento contenidas en las resoluciones de calificación ambiental, en casos de incumplimiento de condiciones o de efectos no previstos (artículo 3 , letras $\mathrm{g}$ y h). En el caso de medidas provisionales, es decir, de los casos ii) y iii), lo que prevé la Ley (párrafos cuarto y quinto del artículo 48) es la necesidad de obtener autorización previa - en tiempo breve-del tribunal ambiental, mientras que en el caso de las sanciones lo que exige es "consulta" para la ejecución de unas resoluciones ya adoptadas (artículo 57). De todas formas, la Ley 20.600, que reitera por remisión estas previsiones (artículo I7·4), se refiere a todos estos supuestos como de autorización. 
del domicilio o supongan entrada en lugares cerrados sin acceso público ${ }^{13}$. En cualquier caso, y desde la perspectiva que aquí importa, los tribunales ambientales chilenos no toman por sí mismos decisiones cautelares en esos casos, sino que revisan la legalidad de las previstas o acordadas por la Administración en el marco de procedimientos administrativos de carácter sancionador, por lo que el equivalente español — no del todo exacto, por tratarse en nuestro caso de una revisión a posteriori- sería la revisión en vía contencioso-administrativa de medidas análogas ${ }^{14}$.

\section{EL SISTEMA CAUTELAR AMBIENTAL CHILENO}

La Ley que Crea los Tribunales ambientales chilenos contiene una regulación de las medidas cautelares común para todos los asuntos de su competencia (artículo 24), pero la variedad de estos asuntos, evidenciada por las distinciones anteriores, permite entender algunos aspectos de esta regulación difícilmente comprensibles si solo se tuviera presente a efectos comparativos la regulación de la materia en nuestras leyes procesales civil y contencioso-administrativa ${ }^{15}$.

13 Artículo 8.6 de la Ley 29/ı998, del I3 de julio, reguladora de la jurisdicción contencioso-administrativa: "Conocerán también los juzgados de lo contencioso-administrativo de las autorizaciones para la entrada en domicilios y restantes lugares cuyo acceso requiera el consentimiento de su titular, siempre que ello proceda para la ejecución forzosa de actos de la administración pública”.

14 No valdría como equivalente la mencionada autorización judicial para la ejecución forzosa de actos administrativos que conlleven entrada en domicilio, además de por su ámbito más reducido, por no implicar una revisión plena de la legalidad de aquellos (véase al respecto, por todas, la sentencia del Tribunal Constitucional $\mathrm{r}_{39} / \mathbf{2 0 0}$, del I3 de septiembre, fundamento jurídico 2), mientras que la que acometen los tribunales ambientales chilenos con motivo de las indicadas autorizaciones sí parece serlo en ambos casos (medidas provisionales y sanciones). Así, por ejemplo, en relación con las medidas provisionales, la sentencia del Tercer Tribunal Ambiental chileno del 5 de marzo de 2020, extracciones de áridos (considerando primero): "Al tratarse de una medida con fines cautelares de máxima injerencia - como es la detención de funcionamiento de instalaciones-, la SMA debe suministrar antecedentes suficientes para establecer sus supuestos básicos: a) apariencia de buen derecho; b) peligro en la demora; c) proporcionalidad”. Del mismo modo, en relación con las sanciones, la sentencia del 9 de mayo de 2018, del caso Plantel de cerdos Santa Josefina (considerando segundo), señala que la revisión ha de ser "plena", debiendo abarcar "tanto el procedimiento como los hechos y el derecho aplicado en la resolución sancionatoria, incluyendo, desde luego, la proporcionalidad de la sanción", sin perjuicio de "una futura pretensión anulatoria que pueda ejercer el sancionado".

15 Ley I/2000, del 7 de enero, de Enjuiciamiento Civil artículos 72r a 747; y Ley 29/ı998, del I3 de julio, Reguladora de la Jurisdicción Contencioso-administrativa, artículos i29 a I36. 
En efecto, en primer lugar, la regulación chilena permite que las medidas cautelares sean adoptadas también "de oficio" ${ }^{16}$, y no solo a instancia de parte, lo que no cabe en nuestros procesos civiles y contencioso-administrativos, pero sí en cambio en el marco de los procedimientos administrativos ${ }^{17}$. Es justamente en los procesos de reparación por daño ambiental, equivalentes entre nosotros a procedimientos administrativos, que los tribunales ambientales chilenos hacen uso con mayor frecuencia - como veremos-de esta posibilidad.

En segundo lugar, también la función de las medidas cautelares está expresada en unos términos distintos a los usuales en el proceso civil y contencioso-administrativo. No se dice, en efecto, que tengan por objeto garantizar el cumplimiento de una eventual sentencia estimatoria, o lo que es lo mismo, evitar que el proceso pierda su finalidad ${ }^{18}$, sino - en términos más amplios, que también comprenden el indicado objetivo- evitar perjuicios a intereses jurídicamente tutelados ${ }^{19}$. También en esto la regulación chilena se aproxima tal vez más a la propia de los procedimientos administrativos -o incluso del proceso penal-, en los que a las medidas provisionales se les asignan unas funciones en todo caso de aseguramiento del éxito de la resolución final, pero que trascienden la perspectiva de la "parte demandante" ${ }^{20}$. Con ello, la regulación chilena permite cubrir de nuevo las necesidades de los procesos de reparación del daño ambiental, equivalentes a nuestros procedimientos administrativos con el mismo objeto.

16 "El Tribunal podrá decretar estas medidas en cualquier estado del proceso o antes de su inicio y por el plazo que estime conveniente. Podrá decretarlas de oficio o a petición de parte, según corresponda, de acuerdo a las normas generales, debiendo en este último caso resolver mediante resolución fundada, sea de plano o con citación” (artículo 24 de la Ley 20.600, párrafo segundo).

17 Artículo 72i de la Ley I/2000; artículo ı29.I de la Ley 29/r998; y art. 56.I de la Ley 39/20I5, del I de octubre, del Procedimiento Administrativo Común de las Administraciones Públicas.

18 Artículos i29 y I30 de la Ley 29/1998 ("Asegurar la efectividad de la sentencia” y "Evitar que el recurso pierda su finalidad legítima”); y artículo 721 de la Ley I/2000 ("Asegurar la efectividad de la tutela judicial que pudiera otorgarse en la sentencia estimatoria que se dictare”).

19 "Con el fin de resguardar un interés jurídicamente tutelado y teniendo en cuenta la verosimilitud de la pretensión invocada, el Tribunal podrá decretar las medidas cautelares, conservativas o innovativas, necesarias para impedir los efectos negativos de los actos o conductas sometidos a su conocimiento" (artículo 24, párrafo primero). Aunque también se dice después que tanto las medidas conservativas como las innovativas tienen por objeto "asegurar el resultado de la pretensión”.

20 Artículo 56.I de la Ley 39/20I5 (“Asegurar la eficacia de la resolución que pudiera recaer”). 
En lo demás, la regulación chilena no presenta grandes novedades respecto de los estándares comunes: i) se consignan los requisitos tradicionales para la adopción de este tipo de medidas, es decir, el fumus boni iuris y el periculum in mora, aunque sobre este tema habremos de volver más adelante ${ }^{21}$; ii) se contempla un catálogo abierto de medidas cautelares posibles, clasificándolas en "conservativas" e "innovativas", tipología que no es desconocida entre nosotros a nivel doctrinal ${ }^{22}$, aunque no hace uso de ella nuestra legislación ${ }^{23}$; iii) en materia de procedimiento, junto a la regla general de la adopción de estas medidas de manera contradictoria y en el marco de un proceso ya iniciado, se prevé del mismo modo su posible adopción inaudita parte o con anterioridad al inicio del proceso, es decir, de forma cautelarísima, como ya ocurre entre nosotros en todos los ámbitos relevantes a efectos comparativos ${ }^{24}$; iv) se prevé la posibilidad de pedir caución o contracautela; y v) se contempla también la posibilidad de revisión de las medidas acordadas ${ }^{25}$.

\section{LAS MEDIDAS CAUTELARES EN LAS RECLAMACIONES DE ILEGALIDAD Y EN EL CONTENCIOSO-ADMINISTRATIVO ESPAÑOL}

\section{I. Las medidas cautelares en las reclamaciones de ilegalidad}

El número todavía moderado de causas conocidas desde la entrada en funcionamiento del Tercer Tribunal Ambiental de Chile, al que vamos a ceñir este estudio, y la excelente información tanto estadística como documental de las causas que proporciona su sitio web, permiten tener una idea bastante aproximada de los tipos de asuntos en los que se

21 Véase infra, apartado 4.2.

22 Belén Marina Jalvo, Medidas provisionales en la actividad administrativa (Valladolid: Lex Nova, 2007), I 4 O; y Andrea Toledo Martín, "Las medidas provisionales en el derecho alimentario", tesis doctoral, Universidad de Navarra, 2012, 298. También, de la misma autora, Las medidas provisionales en el derecho alimentario y la responsabilidad patrimonial de la Administración por su adopción (Cizur Menor: Thomson Reuters Aranzadi, 2013).

23 Para las innovativas se establecen especiales requisitos: "La cautela innovativa solo podrá decretarse ante la inminencia de un perjuicio irreparable. Si el Tribunal estimare que no concurren las circunstancias que la hagan procedente podrá, de oficio, decretar la medida cautelar que a su juicio corresponda” (artículo 24 , párrafo sexto).

Artículo 24, párrafo segundo, ya transcrito. No parecen exigirse especiales razones de urgencia para la adopción de medidas "antes del inicio" del proceso o "de plano", pero se prevé "audiencia" en caso de oposición a las medidas solicitadas o acordadas y de petición de alzamiento de las medidas (artículo 24, párrafo cuarto).

25 Artículo 24, párrafos tercero y cuarto, respectivamente. 
plantea más a menudo la adopción de medidas cautelares, así como de otras cuestiones relevantes, como su otorgamiento o denegación, contenido de las medidas y más ${ }^{26}$.

En el campo de las reclamaciones de ilegalidad, la apertura de incidentes cautelares no parece ser muy frecuente. La mayor parte de las solicitudes - si no todas- se producen con motivo de la impugnación de actos de aprobación o autorización de proyectos, lo que por lógica tiene como finalidad principal la suspensión de su eficacia durante la tramitación del proceso (medida conservativa), y - salvo error por mi parte- las resoluciones favorables son hasta la fecha escasas ${ }^{27}$, mientras que algunas solicitudes quedaron sin necesidad de pronunciamiento debido tal vez a la rapidez en dictar sentencia de fondo, $y$ con el resto mayoritariamente desestimadas.

Ninguna petición de medidas cautelares parece haberse producido con motivo de la impugnación de actos denegatorios de la aprobación o autorización de proyectos, que tendría por fin la obtención de lo que en España se denominan medidas cautelares positivas, esto es, el otorgamiento provisional durante la tramitación del proceso de la aprobación o autorización denegada (medida innovativa).

Tampoco se solicitan medidas cautelares con motivo de la impugnación de sanciones impuestas por incumplimientos de la legislación ambiental (multas, a veces de elevada cuantía), lo que sin duda se debe a que en el derecho chileno las sanciones administrativas no son ejecutivas hasta que no alcanzan firmeza ${ }^{28}$.

Como es comprensible, tampoco parece que se hayan pedido nunca medidas cautelares en caso de impugnación de decisiones de archivo de denuncias, cuyo otorgamiento se traduciría en una anticipación improcedente de la sanción o del procedimiento sancionador.

26 En este trabajo he intentado adquirir una idea del funcionamiento del sistema cautelar ambiental chileno a partir de la lectura de resoluciones del Tercer Tribunal Ambiental, facilitada por su encomiable transparencia. Quizás por ello algunas de mis valoraciones, condicionadas además siempre por el enfoque comparativo del trabajo, no coincidan con las que, obviamente con mayor conocimiento y autoridad, se expresan en la propia doctrina chilena, por ejemplo, Elena Isabel Valenzuela Silva, "La tutela cautelar ante los tribunales ambientales", memoria para optar al grado de Licenciado en Ciencias Jurídicas y Sociales, Universidad de Chile, 2org.

27 Por ejemplo, el caso del proyecto Tronadura. La Resolución del ı6 de noviembre de 2018 otorgó la medida cautelar solicitada por entender concurrentes los requisitos del fumus boni iuris y del periculum in mora (restos paleontológicos), así como la idoneidad y proporcionalidad de la suspensión de las voladuras.

28 El artículo 56, párrafo segundo, de la Ley 20.4I7 señala: "Las resoluciones que impongan multas serán siempre reclamables [ante el Tribunal Ambiental] y aquellas no serán exigibles mientras no esté vencido el plazo para interponer la reclamación, o esta no haya sido resuelta”. 


\subsection{Breve repaso de la evolución de la tutela cautelar en el contencioso-administrativo español}

La situación en el derecho español, por lo que se refiere al término de comparación apropiado en este caso - es decir, la tutela cautelar en los procesos contencioso-administrativos de temática ambiental-, es muy diferente tanto desde el punto de vista cuantitativo como cualitativo. El número de incidentes es inabarcable y la naturaleza de los asuntos mucho más variada, por lo que desborda de manera amplia, por lo que respecta a la impugnación de actos administrativos, la temática de las evaluaciones ambientales — que no obstante también es en España una materia objeto de frecuente litigiosidad y consiguiente solicitud de medidas de suspensión-; incluyendo en ese mismo campo la petición de medidas positivas en caso de denegación de autorizaciones y de suspensión en caso de sanciones - que en derecho español son ejecutivas una vez firmes en vía administrativa ${ }^{29}-\mathrm{y}$ también con toda normalidad la solicitud de medidas cautelares en procesos que tienen por objeto la impugnación de disposiciones generales o instrumentos de planeamiento ${ }^{30}$.

No se me ocurre un modo mejor de afrontar la comparación prometida que comenzar con una somera exposición de la evolución - legislativa, jurisprudencial y doctrinal- del sistema cautelar español en el ámbito del proceso contencioso-administrativo, lo que haremos en el presente apartado ${ }^{31}$, para continuar después con algunas consideraciones específicas sobre la aplicación del sistema actual en asuntos de temática ambiental, lo que llevaremos a cabo en el apartado siguiente.

De manera convencional, vamos a distinguir en la referida evolución cuatro momentos o etapas: i) la que se abre con la aprobación de la Ley de la Jurisdicción Contencioso-administrativa de $1956^{32}$; ii) la que se inicia, bajo la vigencia todavía de esa ley, con la aprobación

29 Si bien en vía contencioso-administrativa se solicita la suspensión, hay que esperar a que el órgano judicial resuelva el incidente (artículo 90.3 de la Ley 39/20I5).

30 Un excelente repertorio de decisiones cautelares, demostrativo de la variedad y riqueza de esta parte de la jurisprudencia contencioso-administrativa española, en una materia bien definida, como es la de los planes y proyectos afectantes a espacios naturales protegidos, en María Soledad Gallego Bernard, La red Natura 2000 en España: Régimen jurídico y análisis jurisprudencial (Madrid: SEO/BirdLife, 2014), 36 r y ss.

31 La bibliografía española en la materia es por supuesto abundantísima y de gran calidad. Baste citar ahora, por contener una visión sintética y amplias referencias doctrinales, el reciente trabajo de Anabelén Casares Marcos, "Eficacia de las medidas cautelares en lo contencioso-administrativo", en 20 años de la Ley de lo contencioso-administrativo, coord. por Fernando López Ramón y Julián Valero Torrijos (Madrid: Instituto Nacional de Administración Pública, 20I9), 355 y ss.

32 Ley de 27 de diciembre de 1956 , Reguladora de la Jurisdicción Contencioso-administrativa. 
de la Constitución española de 1978; iii) la batalla doctrinal por las medidas cautelares de los años noventa; y iv) la etapa actual que principia con la aprobación de la vigente Ley de la Jurisdicción Contencioso-administrativa de 1998 (Ley 29/1998).

\subsection{Ley de la Jurisdicción Contencioso-administrativa de 1956}

La espléndida Jurisdicción Contencioso-administrativa de 1956 contenía una regulación de las medidas cautelares (artículos 122 a 125) posiblemente razonable a la luz de las características del sistema administrativo y contencioso-administrativo español del momento, y en el fondo no muy distinta, como veremos, de la regulación actual.

Partiendo de la presunción general de legalidad atribuida en el derecho español a los actos administrativos - y disposiciones generales - y de la autotutela concedida también con carácter general en nuestro ordenamiento a la Administración para la ejecución de sus actos, la ley concebía lógicamente la suspensión de la ejecución de actos y disposiciones en vía de recurso contencioso-administrativo - única medida cautelar prevista de manera expresa- como una excepción a la regla general de su eficacia -incluida, en su caso, la posibilidad de ejecución forzosa-durante la tramitación del recurso ${ }^{33}$.

De todas formas, se consideraba procedente la suspensión cuando la ejecución del acto o disposición pudiera causar "perjuicios de reparación imposible o difícil" ${ }^{34}$, salvo que de ella pudiera seguirse una "grave perturbación a los intereses públicos" (artículo 123.2), caso en el cual se entraba en el terreno de la "ponderación" ${ }^{35}$, y condicionada en caso afirmativo a la constitución de caución si de la suspensión "pudiera resultar algún daño o perjuicio a los intereses públicos o de tercero" (artículos 123.2 y 124.1, respectivamente).

33 "La interposición del recurso contencioso-administrativo no impedirá a la Administración ejecutar el acto o la disposición objeto del mismo, salvo que el Tribunal acordare, a instancia del actor, la suspensión" (artículo I22.I).

34 "Procederá la suspensión cuando la ejecución hubiese de ocasionar daños o perjuicios de reparación imposible o difícil” (artículo i22.2).

35 "Al juzgar sobre su procedencia [de la suspensión] se debe ponderar, ante todo, la medida en que el interés público exija la ejecución, para otorgar la suspensión, con mayor o menor amplitud, según el grado en que el interés público esté en juego" (preámbulo de la Ley, apartado 5·7). 
Aunque la aplicación de estas previsiones fue al parecer durante mucho tiempo poco favorable a la suspensión ${ }^{36}$, la propia ley en su preámbulo (apartado 5.7) se cuidaba de señalar que el simple carácter económico de los perjuicios derivados de la ejecución no excluía necesariamente su dificultad de reparación.

\subsubsection{La Constitución española de 1978}

La entrada en vigor de la Constitución de 1978, con el reconocimiento - entre otros-del derecho fundamental a la tutela judicial efectiva (artículo 24.1), supuso sin duda un cambio importante en el tratamiento de las medidas cautelares en todos los órdenes jurisdiccionales y, en particular, por lo que aquí importa, en el contencioso-administrativo. Aunque la jurisprudencia constitucional nunca ha cuestionado la constitucionalidad de la autotutela de las Administraciones públicas, conectándola incluso con el principio de eficacia de la actuación administrativa (artículo 103.1), también se cuidó temprano de señalar que la obtención de la tutela cautelar, en los casos en que resultara procedente, constituía un derecho fundamental, como corolario del derecho a la tutela judicial efectiva ${ }^{37}$.

De todos modos, la atribución a la tutela cautelar de una dimensión constitucional, trascendente a la legalidad ordinaria, más allá de generar una actitud más favorable al otorgamiento de este tipo de medidas, no supuso tampoco por sí sola un cambio radical en la jurisprudencia española en la materia, por dos motivos. En primer lugar, porque la Ley de 1956 ya contemplaba el supuesto con relevancia desde el punto de vista del derecho a la tutela judicial efectiva (perjuicios de difícil o imposible reparación), de modo que en este punto podía entenderse acomodada a la Constitución. En segundo lugar, por las propias características del recurso de amparo, que impedían que cualquier denegación

36 Considerándose, por ejemplo, en general los perjuicios puramente económicos como fácilmente reparables, dada la solvencia de las Administraciones públicas. Por ejemplo, entre otros muchos, los autos del Tribunal Supremo del i2 de febrero de 1972 y del 17 de marzo de 1972 , en materia de tributos. Pero también se otorgaban suspensiones en caso de perjuicios económicos. Así, por ejemplo, el auto del 22 de diciembre de i967, que confirmó la suspensión de la orden de cierre de una industria molesta, o el auto del I $_{4}$ de abril de 1978 , que confirmó la suspensión de una licencia de obras para la construcción de un edificio de varias plantas, argumentando cabalmente sobre las consecuencias en todo caso indeseables de la estimación del recurso con el edificio ya construido. Para consultar la jurisprudencia española cabe acudir, entre otras fuentes, a la espléndida base de datos del Consejo General del Poder Judicial, http://www.poderjudicial.es/cgpj/es/Servicios/Jurisprudencia/Buscador-Fondo-Documental-Jurisprudencia/.

37 Entre otras, las sentencias 66/1984 (fundamento jurídico 3 ) y 238/1992 (fundamento jurídico 3 ), del Tribunal Constitucional. 
de medidas cautelares pudiera por este solo hecho ser objeto de revisión plena por el Tribunal Constitucional ${ }^{38}$.

\subsubsection{La batalla doctrinal por las medidas cautelares}

Un cambio más profundo del statu quo hubiera supuesto el éxito de la "batalla por las medidas cautelares", emprendida en los años noventa por el gran maestro del derecho administrativo español, el profesor Eduardo García de Enterría ${ }^{39}$. A partir de la incardinación de la tutela cautelar dentro del derecho fundamental a la tutela judicial efectiva, pero también de la posición constitucional de las Administraciones públicas (sometimiento pleno a la ley y al derecho e interdicción de la arbitrariedad de los poderes públicos, artículos 103.1 y 9.3 de la Constitución, respectivamente), y con el propósito de servir de correctivo a los abusos de la autotutela administrativa, favorecidos por la larga duración de los procesos, lo que venía a proponer la tesis del profesor García de Enterría era la consideración del fumus boni iuris como condición suficiente para el otorgamiento de la medida cautelar - de suspensión u otra - en los casos en los que un examen preliminar del asunto pusiera claramente de manifiesto la ilegalidad del acto o disposición impugnados, relativizando en cambio o dando por supuesta en la generalidad de los casos la existencia del periculum in mora (de los perjuicios de difícil o imposible reparación).

La brillantez con que venía expuesta, unida al prestigio de su autor, hizo que esta tesis hallara temprana acogida en la jurisprudencia contencioso-administrativa española ${ }^{20}, \mathrm{y}$ que haya mantenido en ella una presencia constante, pero sin alcanzar nunca un éxito pleno y generalizado, como hemos de ver.

\subsubsection{La vigente Ley de la Jurisdicción Contencioso-administrativa de 1998}

En efecto, en plena "batalla por las medidas cautelares" se aprobó la vigente Ley 29/1998 de 1998, cuya regulación de las medidas cautelares (capítulo 2 del título 6, artículos 129 a 136) no supuso ninguna revolución, y el primero en constatarlo y en mostrar su decepción por ello fue el propio profesor García de Enterría ${ }^{41}$.

38 A este respecto, me permito recomendar la lectura del espléndido trabajo de José María Rodríguez de Santiago, "El artículo 24.I CE como 'norma de conducta' para jueces y tribunales y 'norma de control' para el Tribunal Constitucional”, Revista Española de Derecho Constitucional $_{74}$ (2005): 26r y ss.

39 Véase al respecto, entre otros muchos trabajos del autor, Eduardo García de Enterría, La batalla por las medidas cautelares (Madrid: Civitas, I992).

40 Así, por ejemplo, el auto del Tribunal Supremo del I7 de febrero de i99i (requerimiento de pago por ejecución subsidiaria de obras ya realizadas).

41 Eduardo García de Enterría, "Observaciones sobre la tutela cautelar en la nueva Ley de la Jurisdicción Contencioso-administrativa de i998”, Revista de Administración Pública I5I (2000): $25^{\mathrm{I}}$ y ss. 
Pese a las ufanas palabras de la exposición de motivos de la Ley a este respecto (apartado 6.5), la nueva regulación contiene novedades limitadas, que no afectan de manera sustancial al fondo de las cosas. Se cambia, eso sí, la denominación y el alcance del capítulo, que no se refiere ya exclusivamente a la suspensión, sino en general a las "medidas cautelares", lo que posibilita la adopción de medidas "positivas", como de todas formas se venía aceptando por la jurisprudencia, aunque sigan siendo menos frecuentes en la práctica ${ }^{22}$. Desde luego se introducen también novedades procedimentales relevantes, comunes hoy a todos los órdenes jurisdiccionales y aun al procedimiento administrativo, como la posibilidad de adopción de esas medidas inaudita parte en casos de especial urgencia, e incluso con carácter previo a la interposición del recurso para ciertas pretensiones deducibles en vía contencioso-administrativa (medidas ambas que se suelen denominar cautelarísimas) ${ }^{43}$.

Pero por lo que se refiere al fondo del asunto, es decir, a los criterios relevantes para la adopción de estas medidas, no hay cambios significativos. Ninguna mención se hace del fumus boni iuris, ni como condición necesaria ni mucho menos como condición suficiente ${ }^{44}$. El criterio determinante sigue siendo el periculum in mora, que, en lugar de venir expresado en términos de perjuicios de difícil o imposible reparación, lo es ahora,

42 Así, por ejemplo, las sentencias del Tribunal Supremo del ir de octubre de 2012 (recurso $5666 / 20$ II) y del I8 de julio de 20 I7 (recurso 2559/20I6), sobre denegación de autorizaciones ambientales integradas, que no conceden las medidas cautelares positivas solicitadas.

43 Adopción de medidas inaudita parte (artículo I35). Las medidas cautelarísimas (artículo I36) solo están previstas frente a la inactividad material y las vías de hecho. Ejemplo reciente de medida inaudita parte es la acordada por auto del 5 de julio de 2019 del $24^{\circ}{ }^{\circ}$ Juzgado de lo Contencioso Administrativo de Madrid (recurso 298/2019), que suspende la moratoria de tres meses acordada por el nuevo Gobierno municipal madrileño en la aplicación de la ordenanza municipal de cierre al tráfico de la zona denominada "Madrid Central", en un recurso interpuesto por la organización ecologista Ecologistas en Acción.

44 Que la legislación española no haya incluido nunca, ni antes ni ahora, la "apariencia de buen derecho" (fumus boni iuris) como requisito para la obtención de medidas cautelares en el orden jurisdiccional contencioso-administrativo puede deberse a la desigual posición de partida de las partes en este tipo de procesos (presunción de legalidad de los actos y disposiciones y autotutela de la Administración), a diferencia de lo que ocurre en los procesos civiles, en los que tal requisito tiene su origen, y al deseo de no agravar más esa desigualdad de partida. A ello hace referencia, por ejemplo, la sentencia del Tribunal Supremo del 8 de mayo de 20I5 (recurso 3957/20I4), fundamento jurídico I5 (revocación de autorización de producto fitosanitario): "Expresamente prevista [la apariencia de buen derecho] en el proceso civil, en donde tiene su ámbito natural [...], en este orden jurisdiccional [el contenciosoadministrativo] se parte de un presupuesto - acto, disposición- cuya legalidad se presume en cuanto ejercicio de una potestad llamada a satisfacer intereses generales". 
en otros equivalentes, como la necesidad de evitar que el recurso pierda su finalidad ${ }^{45}$. Se mantiene también la excepción a la excepción, es decir, la posibilidad de denegar las medidas cuando su otorgamiento pudiera causar una grave perturbación para otros intereses no solo públicos, sino también de naturaleza privada ${ }^{46}$. Es entonces cuando debe entrar en juego la "ponderación" de todos los intereses en presencia ${ }^{47}$. Solo en el caso de que se entienda procedente la medida es cuando cabe entrar a valorar la pertinencia o no de exigir una caución para poner a resguardo esos otros intereses, que en ningún caso constituye una exigencia ineludible ${ }^{48}$.

El tenor legal es suficientemente claro y hay muchas resoluciones del Tribunal Supremo que resumen los criterios aplicables en la actualidad en derecho español para la adopción de medidas cautelares en el orden contencioso-administrativo ${ }^{49}$. El periculum in mora y la ponderación son los criterios básicos y determinantes. El fumus boni iuris, esto es, la "mirada de soslayo" al fondo del asunto, no tiene la misma importancia, porque, como afirma con reiteración esa jurisprudencia, otro de los elementos estructurales básicos de la tutela cautelar es la abstracción de la cuestión de fondo, sin cuyo respeto se vulneraría el derecho también fundamental a un proceso con todas las garantías (artículo 24.2 de la Constitución). Solo en casos puntuales y bien acotados el fumus boni iuris puede ser

45 "Previa valoración circunstanciada de todos los intereses en conflicto, la medida cautelar podrá acordarse únicamente cuando la ejecución del acto o la aplicación de la disposición pudieran hacer perder su finalidad legítima al recurso" (artículo I30.I) (el destacado es nuestro).

46 "La medida cautelar podrá denegarse cuando de esta pudiera seguirse perturbación grave de los intereses generales o de tercero que el juez o tribunal ponderará en forma circunstanciada” (artículo I30.2).

47 "El criterio para su adopción consiste en que la ejecución del acto o la aplicación de la disposición pueden hacer perder la finalidad del recurso, pero siempre sobre la base de una ponderación suficientemente motivada de todos los intereses en conflicto" (exposición de motivos de la Ley 29/r998, apartado 6.5).

48 "Cuando de la medida cautelar pudieran derivarse perjuicios de cualquier naturaleza, podrán acordarse las medidas que sean adecuadas para evitar o paliar dichos perjuicios. Igualmente podrá exigirse la presentación de caución o garantía suficiente para responder de aquellos” (artículo I33.I).

49 Así, por ejemplo, la sentencia del 20 de abril de $20 \mathrm{I}_{5}$ (recurso 2598/20I4), fundamento jurídico 8 (plan general); y del I2 de febrero de 2018 (recurso I03/20I7), fundamento jurídico 6 (deslin-

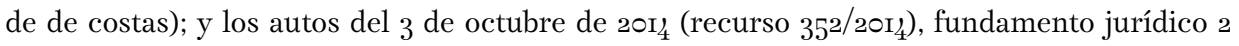
(gestión de residuos radioactivos) y del 28 de marzo de 2019 (recurso 47/20I9), fundamentos jurídicos 3 a 5 (reglamento de retribuciones de la carrera judicial). 
condición suficiente para el otorgamiento de la tutela cautelar ${ }^{50}$. En los demás, se mantiene la pertinencia de tomarlo en consideración, y muchas veces se analiza, pero bajo las pautas ya indicadas.

Todo esto no quiere decir que la jurisprudencia cautelar española sea hoy en día tan restrictiva como lo era en otros tiempos. Se conceden muchas medidas cautelares, como veremos a continuación en el campo ambiental, pero es fruto tal vez más de la impronta constitucional ya mencionada que de los cambios legislativos, como hemos visto, modestos.

\subsection{Algunas consideraciones especiales sobre la tutela cautelar en los contenciosos ambientales}

La aplicación de estos criterios generales en casos de temática ambiental permite hacer algunas consideraciones adicionales, aunque probablemente no exclusivas de esta materia.

\subsection{Interés prevalente}

Los asuntos de temática ambiental - en concreto, la impugnación de actos o disposiciones que pueden ser perjudiciales para el medio ambiente-cuentan de entrada con una ventaja en materia cautelar, que se debe a la muy extendida consideración por parte de la jurisprudencia de los intereses ambientales como preferentes o prevalentes a estos efectos $^{51}$. La justificación de este trato preferencial se hace en ocasiones apelando a la

50 Así, entre otras muchas, la sentencia del Tribunal Supremo del I 4 de diciembre de 2016 (recurso $37 \mathrm{I}_{4} / 20 \mathrm{I}_{5}$ ), fundamento jurídico 8 (sanción de clausura temporal de la instalación): "La doctrina de la apariencia de buen derecho, tan difundida, cuan necesitada de prudente aplicación, debe ser tenida en cuenta al solicitarse la nulidad de un acto dictado en cumplimiento o ejecución de una norma o disposición general declarada previamente nula de pleno derecho o bien cuando se impugna un acto idéntico a otro ya anulado jurisdiccionalmente, pero no [...] al predicarse la nulidad de un acto en virtud de causas que han de ser, por primera vez, objeto de valoración y decisión, pues de lo contrario se prejuzgaría la cuestión de fondo, de manera que por amparar el derecho a la efectiva tutela judicial, se vulneraría otro derecho, también fundamental y recogido en el propio artículo 24 de la Constitución, cual es el derecho al proceso con las garantías debidas de contradicción y prueba”.

51 Así, por todas, sentencia del Tribunal Supremo del 9 de julio de 2012 (recurso r2ı3/2010), que confirma la suspensión de la orden de exclusión del catálogo de especies amenazadas de Canarias de la población de un alga (la seba o Cymodocea nodosa) en la superficie marina donde se iba a construir un puerto: "Así hemos declarado que cuando se trata de realizar la valoración circunstanciada de los intereses en conflicto, del tan citado artículo I30.I de la [Ley 29/r998], tiene carácter prevalente el interés medioambiental” (fundamento jurídico 6). Véase, ya tempranamente y con detalle al respecto, Jesús Jordano Fraga, "El proceso de afirmación del medio ambiente como interés público prevalente o la tutela cautelar ambiental efectiva: La suspensión de los actos administrativos por razón de la protección del medio ambiente en la jurisprudencia del TS”, Revista de Administración Pública I45 (I998): I69 y ss. 
relevancia constitucional y a escala internacional de la protección del medio ambiente, pero tiene una explicación más sencilla y coherente con las reglas del juego que presiden la adopción de medidas cautelares (periculum in mora y ponderación), que estriba en el carácter irreparable o difícilmente reparable que en general se atribuye a todo daño ambiental, así como en la naturaleza colectiva que por definición presentan este tipo de daños, es decir, su afectación a los intereses generales ${ }^{52}$.

Por el mismo tipo de razones, se encuentra en cambio en una posición al comienzo desventajosa a efectos cautelares la impugnación de actos o disposiciones que, aunque el examen del fondo del asunto revele más tarde su disconformidad con el ordenamiento jurídico, tiene un componente de protección ambiental ${ }^{53}$.

\subsubsection{Casuismo}

Lo anterior no quiere decir que baste con la simple alegación de que la ejecución del acto o disposición impugnados puede producir un daño ambiental para obtener la suspensión, pues el juicio cautelar, a partir de su propia configuración legal, y así es asumido también en forma unánime por la jurisprudencia, es un juicio eminentemente casuístico, vinculado a las circunstancias del caso, y en el que pueden entrar en juego varios factores ${ }^{54}$.

En primer lugar, es obvio que, aunque se acepte que los daños ambientales tienen por regla general un carácter irreparable o difícilmente reparable, no todo daño ambiental reviste la misma importancia, ni todos los daños ambientales son en realidad irreparables o de difícil reparación. Aunque la jurisprudencia contencioso-administrativa no exige, como sí hace en los asuntos de su competencia la jurisprudencia constitucional, que se acredite en estos casos la "certeza e inmediatez" de los daños ${ }^{55}$, lo bien cierto es que en todo caso

52 En este sentido se expresa también la jurisprudencia constitucional en las decisiones cautelares que adopta dentro de su esfera de conocimiento. Así, por ejemplo, el auto del Tribunal Constitucional 355/2007 (desaladora de Torrevieja), fundamento jurídico 3 .

53 Así, por ejemplo, la sentencia del Tribunal Supremo del 23 de noviembre de 2016 (recuso $3^{825 / 2015}$ ), que deniega la suspensión de la sanción de clausura temporal de una instalación de tratamiento de residuos por la prevalencia del interés ambiental cuya protección persigue la resolución recurrida (fundamento jurídico 3).

54 Así, entre otras muchas, la sentencia del Tribunal Supremo del i6 de julio de 2012 (recurso $55^{63} / 2010$ ), impugnación de un plan para la explotación de canteras en suelo no urbanizable: "La invocación de precedentes jurisprudenciales en una materia de elevado casuismo, como la presente, no resulta eficaz si se prescinde de las circunstancias concretas de cada caso" (fundamento jurídico 6).

55 Jurisprudencia a mi juicio criticable y que no se sigue de un modo coherente. Así, por ejemplo, los autos 56/2010 (parany) y II/20II (Meseta Sky) del Tribunal Constitucional. Me he ocupado por extenso de esta cuestión en Germán Valencia Martín, Jurisprudencia constitucional y medio ambiente (Cizur Menor: Thomson Reuters Aranzadi, 20I7), I67 y ss. 
resulta necesario un esfuerzo argumentativo tendente a concretar las características de los daños que se invocan y la relación de causa-efecto entre la ejecución del acto o disposición y su producción, a partir de lo cual poder calibrar su entidad. La falta de ese esfuerzo argumentativo conduce a veces al rechazo de las peticiones de tutela cautelar.

En segundo lugar, lo que se impugna muchas veces son actos o disposiciones que, aunque en opinión de los recurrentes son ilegales y van a producir daños ambientales, vienen precedidos de una evaluación de sus repercusiones ambientales que los considera aceptables desde este punto de vista y que incluye medidas correctoras para minimizar esta clase de efectos. Es obvio que en estos casos el solicitante de la suspensión ha de desplegar un esfuerzo argumentativo mayor, pues a los solos efectos cautelares y sin prejuzgar el fondo del asunto, ha de mostrar de forma convincente la insuficiencia de las medidas correctoras previstas y la persistencia, pese a ellas, de posibles daños relevantes ${ }^{56}$.

Por último, aunque se hayan levantado con éxito las anteriores cargas argumentativas, es muy posible que la otra parte contendiente (la Administración) esgrima un conjunto de consecuencias negativas que pueden derivarse de la adopción de la medida cautelar. Es entonces cuando, de acuerdo con las previsiones legales, se entra en el terreno de la ponderación. Si frente al posible perjuicio ambiental - serio - tan solo se esgrimen posibles perjuicios - públicos o privados-de naturaleza económica, la balanza tiende a inclinarse del lado ambiental, por el carácter por definición resarcible que se atribuye a los perjuicios puramente económicos ${ }^{57}$. Ahora bien, cuando al posible perjuicio ambiental se oponen otros que son también de naturaleza colectiva (que afectan a intereses generales) y que trascienden la esfera económica, es decir, que se encuentran al menos al mismo nivel de

56 Así, por ejemplo, la sentencia del Tribunal Supremo del i6 de diciembre de 20Ir (recurso 541/20II), que deniega la suspensión de la autorización ambiental integrada concedida para un vertedero, por las medidas correctoras ya previstas en la autorización para evitar los daños de las obras a ciertas aves rapaces.

57 Así, por ejemplo, sentencia del Tribunal Supremo del i8 de junio de 20 I $_{5}$ (recurso 3074/20I4), que no concede la suspensión de la denegación de autorización de uso de suelo no urbanizable para una explotación minera: "Tales perjuicios [los causados a la empresa de prosperar el recurso] son susceptibles de reparación, sin que, en definitiva, el recurso contencioso-administrativo interpuesto pierda su finalidad [...], mientras que si se accede a la medida cautelar positiva que se solicita a fin de autorizar la extracción, los daños que pudieran causarse al medio resultarían irreversibles aunque quepa la adopción de hipotéticas medidas de restauración” (fundamento jurídico 2). 
relevancia o preferencia, la balanza se puede inclinar de un lado o de otro dependiendo del peso relativo de una y otra clase de perjuicios $^{58}$.

Como resumen de estos tres aspectos, valga la espléndida argumentación desplegada por el Tribunal Supremo al resolver sobre la suspensión —-denegándola en este caso- solicitada con motivo de la impugnación del acto de aprobación de la construcción de un nuevo centro penitenciario en la ciudad de Pamplona ${ }^{59}$.

Más allá de lo anterior, poco más creo que puede decirse en términos generales sobre la manera de resolver estos incidentes cautelares. En particular, no cabe hacer una tipología de asuntos por razón de la materia, que quedaría siempre relativizada por la necesaria

58 Así, por ejemplo, el auto del Tribunal Supremo del $2_{4}$ de julio de $20{ }_{5}$ (recurso 732/20I5), que deniega la suspensión cautelar de ciertas obras portuarias (en un recurso frente a la exclusión de la sujeción a EIA del proyecto portuario "Protección del frente litoral de San Andrés", en Tenerife), porque, aun entendiendo acreditado el periculum in mora (posible daño a las praderas de sebas), en este caso se entiende prevalente (ponderación) el riesgo para la seguridad de las personas (inundaciones recurrentes) que la obra pretende conjurar, teniendo en cuenta además que dichas praderas ya están protegidas en otras zonas próximas y que el proyecto contempla algunas medidas correctoras. O la sentencia del Tribunal Supremo del i6 de diciembre de 2016 (recurso 672/20I6), que otorga la suspensión del acuerdo de iniciación del procedimiento para ampliar un espacio natural protegido, por el impedimento que ello supone para la construcción de un almacén temporal centralizado (ATC) de residuos radiactivos, interés en este caso prevalente: "El perjuicio al interés general que se crea con el acuerdo impugnado no es [...] exclusiva o primordialmente económico, sino que se alega y razona que dicho perjuicio está en el entorpecimiento a la gestión de los residuos radioactivos y, por consiguiente, el debilitamiento de la seguridad nuclear, con lo que se daña un servicio público esencial [...]. Pues bien, si efectuamos un correcto juicio de ponderación entre los intereses enfrentados, nos parece prevalente preservar la adecuada gestión de los residuos radioactivos en orden a una mejor seguridad nuclear, mientras se sustancia el pleito, que la aprobación inmediata de la ampliación de un espacio protegido para las aves" (fundamento jurídico 3 ).

Auto del i6 de abril de 2009 (recurso Iro/2009): "Ahora bien, sucede que la confrontación de intereses a que nos referimos reviste en este caso unas características específicas que no podemos obviar. En primer lugar, porque se trata de realizar una obra pública que cumple una necesidad esencial para la comunidad, como acontece con albergar a la población reclusa. En segundo lugar, porque el interés medioambiental se manifiesta de un modo tenue y difuso a tenor de la propia documentación apartada con la solicitud cautelar [...]. Y, en fin, porque en el propio acto administrativo recurrido se establecen medidas correctoras que, sin perjuicio de lo que se resuelva en la sentencia que recaiga, permiten considerar, de modo provisional y a los efectos cautelares, únicos ahora valorados, que la variable medioambiental ha sido tomada en consideración, valorada y, en su virtud, se han adoptado determinadas medidas al respecto" (fundamento jurídico 3 ). 
atención a las circunstancias concretas de cada caso, aunque en algunas materias se pueden detectar líneas jurisprudenciales consolidadas - así, por ejemplo, en el campo de los instrumentos de planeamiento urbanístico ${ }^{60}$ - . No obstante, vamos a añadir algunas otras consideraciones específicas.

\section{4:3.3. La planta judicial y el sistema de recursos}

En los procesos contencioso-administrativos, las medidas cautelares las decide el mismo juzgado o tribunal que conoce del pleito principal ${ }^{61}$. No hay reglas especiales de atribución de la competencia objetiva a unos u otros órganos judiciales en razón a la temática ambiental de los asuntos, y por ello el conocimiento en primera - o única-instancia de esta clase de asuntos puede corresponder según los casos a toda la gama de juzgados y tribunales que conforman la planta judicial de lo contencioso-administrativo en España ${ }^{62}$. No obstante lo cual, y atendiendo a esas reglas, la mayor parte de los pleitos de temática ambiental, al menos los de cierta entidad, son decididos en primera - en realidad, únicainstancia por las Salas de lo Contencioso-administrativo de los Tribunales Superiores de Justicia, cuyas decisiones (autos) en materia cautelar son recurribles en casación ante la

60 Véase, en este sentido, la sentencia del Tribunal Supremo del 23 de marzo de 20 Ir (recurso $2672 / 20$ Io), que otorga la suspensión de un plan especial para la construcción de viviendas, teniendo en cuenta la ausencia de informe de la Confederación Hidrográfica sobre la suficiencia de recursos hídricos (vicio procedimental grave): "Hay que recordar, como razón adicional para justificar la procedencia de tal suspensión cautelar, que esta Sala Tercera del Tribunal Supremo ha declarado también, entre otras, en sus sentencias [...], que se debe acceder a la suspensión pedida de la ejecutividad de los instrumentos de planeamiento urbanístico o de los actos de ejecución del mismo cuando, durante el tiempo de tramitación del proceso, pudiesen crearse situaciones jurídicas y alteraciones del medio físico difícilmente reversibles, que es lo que sucedería en este caso si no suspendiésemos la ejecución del indicado Plan Especial, objeto de impugnación en el proceso principal" (fundamento jurídico 5; el destacado es nuestro).

61 "Los órganos del orden jurisdiccional contencioso-administrativo que fueren competentes para conocer de un asunto lo serán también para todas sus incidencias y para hacer ejecutar las sentencias que dictaren en los términos señalados en el artículo i०3.I" (artículo 7.I de la Ley 29/1998).

62 "El orden jurisdiccional contencioso-administrativo se halla integrado por los siguientes órganos: a) Juzgados de lo Contencioso-administrativo, b) Juzgados Centrales de lo Contencioso-administrativo, c) Salas de lo Contencioso-administrativo de los Tribunales Superiores de Justicia, d) Sala de lo Contencioso-administrativo de la Audiencia Nacional, y e) Sala de lo Contencioso-administrativo del Tribunal Supremo" (artículo 6 de la Ley 29/1998). 
Sala de lo Contencioso-administrativo del Tribunal Supremo con las mismas limitaciones -no pocas-que las sentencias que resuelvan los pleitos principales ${ }^{63}$.

Quiere ello decir que con un sistema legal y jurisprudencial tan abierto como el español, hay que contar con una cierta potencial variabilidad en cuanto a los criterios para la adopción de medidas cautelares según el órgano judicial (el Tribunal Superior de Justicia) que conozca de la causa, cuyas posibilidades de unificación no son completas por las mencionadas limitaciones de acceso a la casación y las propias características de este recurso ${ }^{64}$.

A este respecto, cabe pensar sobre todo en la relevancia del fumus boni iuris. Aunque - como vimos - el criterio del Tribunal Supremo es muy restrictivo, algunos Tribunales Superiores de Justicia tienden a concederle no poca importancia, precisamente en asuntos ambientales, amparándose en esa línea doctrinal también ya comentada y nunca del todo descartada por la propia jurisprudencia del Supremo ${ }^{65}$. Si una decisión cautelar (de instancia) aparece basada exclusivamente en el fumus boni iuris, será casada por el Supremo ${ }^{66}$, pero si no es así, lo más probable es que sea mantenida en casación, aunque le conceda una importancia superior a la que en línea de principio se desprende de esa doctrina restrictiva ${ }^{67}$.

63 Artículo 87 de la Ley 29/1998. Entre estas limitaciones cabe mencionar ahora sobre todo el "interés casacional objetivo para la formación de jurisprudencia" (artículo 88, en su nueva redacción dada por la Ley Orgánica 7/20I5, del 2i de julio, por la que se modifica la Ley Orgánica 6/1985, del I de julio, del Poder Judicial).

64 Sobre todo con el nuevo recurso de casación y el interés casacional. En este sentido, la sentencia del Tribunal Supremo del i8 de diciembre de 2018 (recurso $4{ }_{4}^{81 / 2017}$ ), en relación con el impuesto catalán sobre grandes establecimientos comerciales (fundamento jurídico 3). Véase el atinado comentario a esta sentencia de Pedro Corvinos Baseca, "Las medidas cautelares y la falta de interés casacional objetivo para formar jurisprudencia”, blog de Pedro Corvinos Abogado, febrero de 20I9, http://pedrocorvinosabogado.es/las-medidas-cautelares-y-la-falta-de-interes-casacional-objetivo-para-formar-jurisprudencia/.

65 Así, por ejemplo, el Tribunal Superior de Justicia de Castilla y León en el auto del 2i de febrero de 2019 (recurso 755/20I8), de suspensión de la regulación autonómica de las especies cazables. Véase el interesante comentario al respecto de Eva Blasco Hedo, "Suspensión provisional de la actividad cinegética por la estimación judicial de una medida cautelar versus modificación de la ley de caza de Castilla y León que autoriza su ejercicio”, Actualidad Jurídica Ambiental 89 (20I9): $47^{-6}$ I.

66 Así, por ejemplo, la sentencia del Tribunal Supremo del 22 de junio de 2010 (recurso 5587/2008), que otorgó la suspensión de un plan especial que había sido denegada en la instancia en base simplemente al fumus (por entender que no tenía vicios).

67 Así, por ejemplo, la sentencia del Tribunal Supremo del II de octubre de 20II (recurso 6608/2010), que confirma la suspensión de la ejecución de un parque eólico, acordada por el Tribunal Superior de Justicia de Castilla y León en base al fumus boni iuirs, aunque no exclusivamente. 


\section{3·4. Los riesgos de la no suspensión}

Las decisiones en materia cautelar tienen siempre mucha importancia práctica, máxime cuando afectan a proyectos de una cierta envergadura. No es infrecuente que, si se acuerda la suspensión, los promotores abandonen esta clase de proyectos, con lo que el pleito principal pierde su objeto y no llegará a sentencia.

Más complejas incluso son las consecuencias cuando la suspensión se deniega, la ejecución del proyecto sigue por tanto su curso y se encuentra terminado y en funcionamiento cuando, finalmente, recae sentencia firme declarando su invalidez. En materia ambiental, y en relación con grandes proyectos, esta situación no es en absoluto infrecuente, porque si los distintos tribunales pueden mantener, como hemos dicho, posiciones más o menos favorables al otorgamiento de la suspensión, todos ellos, con el Tribunal Supremo a la cabeza, mantienen una postura muy exigente en cuanto al cumplimiento formal y sustantivo de la legislación ambiental, sin duda condicionada por la posición también exigente - esta legislación viene siempre encabezada por normativa comunitaria europea-del Tribunal de Justicia de la Unión Europea ${ }^{68}$.

Los problemas a que da lugar la ejecución de sentencias anulatorias de grandes proyectos ya terminados y en funcionamiento - de los actos o disposiciones que los aprueban o autorizan - son incontables, de desenlace variable e incierto, y en todo caso consumen una cantidad ingente de recursos, de preferible destino a mejores causas ${ }^{69}$.

No tienen fácil solución estos problemas, motivados por la larga duración de los procesos, que es la clave del tema de las medidas cautelares ${ }^{70}$. Mejor resuelta, según parece, en el

68 Véase Gallego Bernard, La red..., $3^{6 \mathrm{r}}$ y ss.

69 Sirva como ejemplo el caso Marina Isla de Valdecañas, en el que recurrido en 2007 el acto de aprobación de un proyecto de urbanización a construir dentro de un espacio natural protegido, el Tribunal Superior de Justicia de Extremadura, que había denegado la suspensión cautelar, dictó cuatro años más tarde, con el proyecto ya parcialmente ejecutado y en funcionamiento, sentencia estimatoria del recurso (sentencia del 9 de marzo de 20II, recurso56I/2007), que devino firme al ser confirmada en casación tres años después (sentencia del Tribunal Supremo del 29 de enero de 20I4, recurso 2419/20II). Tras innumerables avatares — de los que me he ocupado con detalle en Germán Valencia Martín, “Transformaciones urbanísticas en la red Natura 2000: El caso Valdecañas”, Revista Aranzadi de Derecho Ambiental 45 (2020): 177 y ss.-, en julio de 2020, el Tribunal Superior de Justicia de Extremadura acordó la imposibilidad (material parcial) de ejecución de su sentencia (artículo ro5 de la Ley 29/1998).

70 A este respecto, Eduardo Salazar Ortuño, El acceso a la justicia ambiental a partir del Convenio de Aarhus (Cizur Menor: Thomson Reuters Aranzadi, 20I9), 248, se muestra partidario de una suspensión cuasi automática de la ejecución de cierto tipo de proyectos, unida a una rápida decisión de los pleitos, a lo que añade otras interesantes propuestas (pp. I97 y ss. y 247 y ss.). 
caso chileno, en el que los pleitos de que conocen los Tribunales Ambientales se resuelven por regla general en cuestión de meses ${ }^{71}$.

\section{LAS MEDIDAS CAUTELARES EN LOS PROCESOS O PROCEDIMIENTOS DE REPARACIÓN DE DAÑOS AMBIENTALES}

Siguiendo el mismo esquema que en el caso de las reclamaciones de ilegalidad, vamos a examinar primero la práctica de los Tribunales Ambientales chilenos en materia cautelar en ese tipo de demandas, para pasar después a referir la legislación y la práctica españolas correspondientes.

\section{I. Las medidas cautelares en las demandas de reparación por daño ambiental}

Este es, según creo, el tipo de procesos en el que los Tribunales Ambientales chilenos se ven con más frecuencia enfrentados a la necesidad de resolver incidentes de naturaleza cautelar. Un somero repaso de algunas de las decisiones adoptadas por el Tercer Tribunal Ambiental permite comprobar, asimismo, que se trata de un campo en el que se explotan casi todas las posibilidades de actuación que ofrece la regulación general, antes expuesta.

En efecto, con motivo de la apertura de esta clase de incidentes, el Tribunal adopta medidas cautelares de los más variados tipos, tanto de carácter conservativo como innovativo, sobre todo dirigidas a la evitación de daños mayores ${ }^{72}$, sobre la base de la apreciación de la concurrencia de los requisitos del fumus boni iuris y del periculum in mora y del principio de proporcionalidad ${ }^{73}$.

71 Este es el caso al menos del Tercer Tribunal Ambiental (Valdivia), como puede comprobarse siguiendo la cronología de las actuaciones de cada asunto, documentada y disponible en su sitio web.

72 Por ejemplo, la Resolución del 7 de diciembre de 2018 (caso Embalse Punilla), que acuerda medidas de ambos tipos (cese de desplazamiento de población y restitución de bienes); las Resoluciones del 9 de agosto de 2019 (casos Humedal Angachilla y Humedal Teja Sur), que disponen medidas solo conservativas (cese de rellenos); y la Resolución del I7 de abril de 20 I9 (caso Municipalidad de Pucón), que adopta solo medidas de carácter innovativo (obras de protección de un camino amenazado de derrumbe).

73 Los requisitos para la adopción de las medidas cautelares por los Tribunales Ambientales chilenos, según jurisprudencia reiterada, son tres: "De lo anterior [el artículo $2_{4}$ de la Ley] se sigue que los requisitos para decretar dichas medidas son: a) la apariencia de buen derecho; b) el peligro en la demora, y; c) para su intensidad, la proporcionalidad" (Resolución del 8 de noviembre de 20r9, caso Humedal Angachilla, considerando sexto). 
Es, además, un campo en el que casi se agotan todas las opciones procedimentales previstas por la ley, incluida la adopción de las medidas antes de la presentación de la demanda ${ }^{74}$. También es frecuente que las decisiones adoptadas se sometan a revisión en una fase posterior del proceso, y que el Tribunal tome entonces en consideración, junto con otras, una circunstancia que aparece expresamente vedada en el ordenamiento español, como son los avances habidos para entonces en el conocimiento y valoración del fondo del asunto ${ }^{75}$.

Es asimismo habitual que el Tribunal despliegue en esta clase de incidentes un amplio arsenal probatorio, incluido el reconocimiento in situ $u^{76}$. No es tampoco infrecuente que el Tribunal haga uso de la facultad que también le otorga la ley de acordar de oficio la adopción de medidas, por ejemplo, en sustitución de otras propuestas y denegadas ${ }^{77}$.

Todo lo anterior constituye en conjunto una práctica sumamente interesante y valiosa, que cuenta además con la máxima transparencia a través del archivo completo de las actuaciones disponible en el sitio web del Tribunal, y que en el fondo viene a ser reflejo de la importancia que, con razón, el Tribunal concede a este apartado de su función.

\subsection{Las medidas provisionales en el procedimiento administrativo español}

La legislación española de alcance general en materia de procedimiento administrativo -la legislación sobre el procedimiento administrativo común- ha contenido por lo general una regulación muy parca de las medidas provisionales, que prácticamente se limitaba a prever su posible adopción en la fase inicial del procedimiento, señalando además su finalidad y estableciendo algunos límites ${ }^{78}$. Así, en la Ley sobre Procedimiento Adminis-

74 Por ejemplo, la ya citada Resolución del caso Embalse Punilla, que constituye una medida cautelar "prejudicial".

75 Así, por ejemplo, también en el caso del Embalse Punilla, en el que por Resolución del 22 de octubre de 20I9 se alzaron las medidas cautelares previamente acordadas, entre otras razones porque a la vista de nuevas evidencias "la verosimilitud preliminar se relativiza" (considerando décimo). Por el contrario, en el derecho español, el artículo I32.2 de la Ley 29/1998 dispone: "No podrán modificarse o revocarse las medidas cautelares en razón de los distintos avances que se vayan haciendo durante el proceso respecto al análisis de las cuestiones formales o de fondo que configuran el debate, y, tampoco, en razón de la modificación de los criterios de valoración que el juez o Tribunal aplicó a los hechos al decidir el incidente cautelar”.

76 Así, en el caso Municipalidad de Pucón (inspección del camino).

77 Así, en el caso Municipalidad de Pucón, en el que se rechazó la medida cautelar innovativa en los términos solicitados, pero se acordó "de oficio" en otros.

78 Sobre este tema, véase, entre otros, José Antonio Tardío Pato, "Medidas provisionales" en El procedimiento administrativo común (comentarios, jurisprudencia, formularios), vol. 2, coord. por José Garberí Llobregat (Valencia: Tirant lo Blanch, 2007), I.I55 y ss.; Marina Jalvo, Medidas...; Toledo Martín, Las medidas.... 
trativo de 1958 (artículo 72) ${ }^{79}$, y después en la Ley 30/1992, en su redacción original (artículo 72$)^{80}$, que añadía una previsión especial de sentido limitativo para el procedimiento sancionador (artículo 136)

Esto propició que la legislación especial - la regulación de los procedimientos administrativos especiales por razón de la materia o de procedimientos administrativos singulares, como el sancionador ${ }^{82}$ - contuviera a menudo regulaciones más detalladas, especificando posibles medidas provisionales o incluyendo algunas variantes procedimentales. Así, por ejemplo, numerosa legislación ambiental ${ }^{83} \mathrm{o}$ la regulación general de los procedimientos administrativos sancionadores ${ }^{84}$.

79 Ley de 17 de julio de $195^{8}$ sobre Procedimiento Administrativo, artículo 72: "ı. Iniciado el procedimiento, la autoridad competente para resolverlo podrá adoptar las medidas provisionales que estime oportunas para asegurar la eficacia de la resolución que pudiera recaer, si existieren elementos de juicio suficientes para ello. 2. No se podrán dictar medidas provisionales que puedan causar perjuicios irreparables a los interesados, o que impliquen violación de derechos amparados por las leyes”.

80 Ley 30/r992, del 26 de noviembre, de Régimen Jurídico de las Administraciones Públicas y del Procedimiento Administrativo Común, artículo 72, "Medidas provisionales": "I. Iniciado el procedimiento, el órgano administrativo competente para resolver, podrá adoptar las medidas provisionales que estime oportunas para asegurar la eficacia de la resolución que pudiera recaer, si existiesen elementos de juicio suficientes para ello. 2. No se podrán dictar medidas provisionales que puedan causar perjuicio de difícil o imposible reparación a los interesados o que impliquen violación de derechos amparados por las leyes".

81 Artículo I36, "Medidas de carácter provisional”: "Cuando así esté previsto en las normas que regulen los procedimientos sancionadores, se podrá proceder mediante acuerdo motivado a la adopción de medidas de carácter provisional que aseguren la eficacia de la resolución final que pudiera recaer" (el destacado es nuestro).

82 Véase, sobre estas distinciones, entre otros, Germán Valencia Martín, "Silencio administrativo común y especial”, Revista Aragonesa de Administración Pública 53 (20I9): I 4 y ss.

83 Por ejemplo, el Real Decreto Legislativo I302/I986, del 28 de junio, de evaluación de impacto ambiental (artículo 9) o la Ley ro/ı998, del 2i de abril, de Residuos (artículos 39 y 40), no vigentes ya.

84 Así, el artículo I5 del Reglamento del Procedimiento para el Ejercicio de la Potestad Sancionadora, aprobado por Real Decreto 1398/1993, del 4 de agosto (no vigente ya), que ampliaba en forma significativa los fines de las medidas provisionales ("necesarias para asegurar la eficacia de la resolución que pudiera recaer, el buen fin del procedimiento, evitar el mantenimiento de los efectos de la infracción y las exigencias de los intereses generales") y los órganos competentes para adoptarlas (junto al órgano competente para resolver, "cuando así venga exigido por razones de urgencia inaplazable, el órgano competente para iniciar el procedimiento o el órgano instructor podrán adoptar las medidas provisionales que resulten necesarias"), señalaba algunos ejemplos ("podrán consistir en la suspensión temporal de actividades y la prestación de fianzas, así como en la retirada de productos o suspensión temporal de servicios por razones de sanidad, higiene o seguridad, y en las demás previstas en las correspondientes normas específicas") y recogía la exigencia de proporcionalidad ("las medidas provisionales deberán estar expresamente previstas y ajustarse a la intensidad, proporcionalidad y necesidades de los objetivos que se pretenda garantizar en cada supuesto concreto"). 
Las cosas empezaron a cambiar con la reforma parcial de la Ley 30/1992 llevada a cabo en 1999, que dio nueva redacción al precepto relativo a las medidas provisionales, dotándolo de un contenido más detallado, que incluía en particular la posibilidad de adelantarlas por razones de urgencia a la iniciación del procedimiento (medidas provisionalísimas) "en los supuestos previstos expresamente por una norma de rango de Ley" (artículo 72.2, en su nueva redacción) $)^{85}$.

Esa tendencia se ha confirmado y afianzado con la nueva ley general en la materia, la Ley 39/2015, cuya regulación de las medidas provisionales (artículo 56), mucho más completa, incluye ahora todo un catálogo - no exhaustivo- de medidas posibles, inspirado en la regulación correspondiente de la Ley de Enjuiciamiento Civil ${ }^{86}$.

La necesidad o conveniencia de ulteriores desarrollos por parte de la legislación especial es ahora, pues, considerablemente menor. Eso no significa que tales desarrollos no sean posibles, siempre y cuando se respeten las previsiones del procedimiento administrativo común, y de hecho la legislación especial suele seguir conteniendo previsiones propias de mayor o menor enjundia. Tal es el caso, por lo que aquí importa, de la ley de responsa-

85 Se añadía también la posibilidad de modificación o alzamiento de las medidas por cambio de circunstancias, así como su extinción cuando surta efectos la resolución (artículo 72.4).

86 Las características principales de la nueva regulación son: i) se mantiene la finalidad clásica de "asegurar la eficacia de la resolución que pudiera recaer"; ii) se mantiene la posibilidad de adoptarlas una vez iniciado el procedimiento o con anterioridad al mismo por razones de "urgencia inaplazable", distinguiendo la competencia en uno y otro caso (el órgano administrativo competente para resolver, en el primero, y el órgano competente para iniciar o instruir el procedimiento, en el segundo); iii) se prevé en ambos casos su adopción de oficio o a instancia de parte; iv) se insiste en el respeto de los "principios de proporcionalidad, efectividad y menor onerosidad"; v) se hace, como ya se ha indicado, todo un listado no exhaustivo de medidas posibles (nueve tipos), entre ellas, la suspensión temporal de actividades, el cierre temporal de establecimientos, la prestación de fianzas y el embargo preventivo de bienes; vi) se mantiene la posibilidad de modificación o alzamiento de las medidas por cambio de circunstancias, así como su extinción cuando surta efectos la resolución; y vii) de manera significativa, no se hace ninguna reserva formal de ley — salvo en la cláusula residual de medidas posibles: "Aquellas otras medidas que, para la protección de los derechos de los interesados, prevean expresamente las leyes" (apartado 3 , letra i) — ni otra clase de condicionamiento a lo previsto en otras normas. Véase, con más detalle, sobre la nueva regulación, Belén Marina Jalvo, "Las medidas provisionales administrativas: Novedades incorporadas por el artículo $5^{6}$ de la Ley 39/20I5, de I de octubre, de Procedimiento Administrativo Común de las Administraciones Públicas”, Revista Vasca de Administración Pública $\mathrm{I} \circ 9$, n. ${ }^{\circ}$ I (2017): 163 y ss. 
bilidad medioambiental ${ }^{87}$, así como de los capítulos sancionadores de las distintas leyes ambientales sectoriales $^{88}$.

\section{5·3. Algunas consideraciones sobre los procedimientos españoles de reparación de daños ambientales}

Aunque no es el momento de desarrollar con detalle esta cuestión, sí conviene explicar brevemente el porqué de esa duplicidad actual en España de procedimientos administrativos para la depuración de responsabilidades por daños ambientales.

La Ley 26/2007, de responsabilidad medioambiental, introdujo en el derecho español, siguiendo las pautas de una directiva comunitaria europea, una nueva regulación de la materia, muy superior a la existente antes en nuestro país, y en virtud de la cual se objetivaba la responsabilidad por daños ambientales para un amplio grupo de actividades económicas, las de mayor riesgo, emancipándola por fin de la exigencia de responsabilidades de carácter sancionador, cuestiones que hasta entonces en el derecho español aparecían indisolublemente unidas ${ }^{89}$. A partir, pues, de la entrada en vigor de esta ley,

87 Ley 26/2007, del 23 de octubre, de Responsabilidad Medioambiental (artículo 44 "Medidas provisionales"), que amplía la finalidad de las medidas a la evitación de daños mayores ("durante la tramitación de los procedimientos se podrán adoptar con carácter provisional todas aquellas medidas preventivas y de evitación de nuevos daños que sean necesarias para que no se agrave la situación, ni se causen daños medioambientales y, especialmente, para garantizar la salud humana”) y contempla su realización directa por la Administración a costa del operador ("las medidas provisionales podrán consistir en imponer al operador la realización de las actuaciones que se juzguen necesarias y que, en caso de incumplimiento, serán susceptibles de ejecución forzosa, así como en actuaciones que haya de realizar la autoridad competente, aun a costa del responsable”).

88 Por ejemplo, la Ley 2I/20I3, del 9 de diciembre, de evaluación ambiental (artículo 59); el texto refundido de la Ley de Prevención y Control Integrados de la Contaminación, aprobado por Real Decreto Legislativo I/20ı6, del r6 de diciembre (artículo 35); o la Ley 22/20ri, del 28 de julio, de residuos y suelos contaminados (artículo 53).

89 Ley 26/2007, del 23 de octubre, de Responsabilidad Medioambiental, que transpone la Directiva $2004 / 35 /$ CE del Parlamento Europeo y del Consejo, del 2i de abril de 2004, sobre responsabilidad medioambiental en relación con la prevención y reparación de daños medioambientales. Véase, sobre esta materia, entre otros, Germán Valencia Martín, "La responsabilidad medioambiental”, Revista General de Derecho Administrativo 25 (2010); y José Miguel Beltrán Castellanos, Instrumentos para la efectividad del régimen de la responsabilidad medioambiental (Cizur Menor: Thomson Reuters Aranzadi, 20I8). A modo de contraste, y sobre el sistema chileno, véase la espléndida tesis doctoral de Jorge Andrés Femenías Salas, "El régimen general de responsabilidad por daño ambiental en la Ley I9.300 sobre bases generales del medio ambiente", Universidad de Valladolid, 20I5; y Jorge Andrés Femenías Salas, La responsabilidad por daño ambiental (Santiago: Universidad Católica de Chile, 2017). 
es posible en España depurar las responsabilidades por daños ambientales -la llamada "responsabilidad medioambiental" - causados por ese tipo de actividades por medio de procedimientos administrativos independientes de los de carácter sancionador, iniciados de oficio o a solicitud de personas interesadas, entre ellas, las organizaciones ecologistas que cumplan unos mínimos requisitos de antigüedad (artículo 42).

Ahora bien, los procedimientos de carácter sancionador previstos por la legislación ambiental sectorial (de aguas, residuos, espacios naturales protegidos, etcétera) siguen desempeñando un papel importante en la exigencia de responsabilidades por daños ambientales por un variado conjunto de razones que podemos resumir como sigue. En primer lugar, porque, aun tratándose de actividades de riesgo - las relacionadas en el anexo 3 de la Ley-, la Ley 26/2007 permite la depuración de esas responsabilidades dentro de un procedimiento sancionador - administrativo o incluso penal- a condición de aplicar las reglas de reparación in natura que constituye otra de sus novedades (disposición adicional novena de la Ley). En segundo lugar, porque para el resto de las actividades económicas causantes de un daño ambiental no rige un sistema de responsabilidad objetiva, sino culposa, y en estos casos la Ley 26/2007 exige que la culpa quede acreditada antes en un procedimiento sancionador (artículo 6.2 letra c). Por último, porque tanto para una clase de actividades como para otra, el presupuesto de la aplicación de la Ley 26/2007 es que el daño ambiental alcance una cierta dimensión, sea "significativo" (artículo 2.1), lo que supone que para daños no significativos la única forma de exigir responsabilidad sigue siendo la tradicional, es decir, la accesoria o derivada de la comisión de una infracción administrativa o de un delito.

Pues bien, por diferentes motivos - tal vez el principal la exigencia de "significatividad" del daño-, la experiencia aplicativa en España del nuevo régimen introducido por la Ley $26 / 2007$, sobre todo por lo que se refiere a los procedimientos independientes para actividades de riesgo, sigue siendo hoy escasa ${ }^{90}$, abundando todavía más los procedimientos sancionadores en los que se depuran al mismo tiempo las responsabilidades por daño ambiental. Pero tanto en un caso como en otro se trata de simples procedimientos administrativos, que no tienen por lógica la publicidad de las resoluciones judiciales, y respecto de los cuales resulta difícil saber con qué frecuencia y en qué términos se adoptan medidas provisionales, salvo que se lleve a cabo una investigación ad hoc que por supuesto no ha sido posible en el marco de este pequeño trabajo.

90 Según el informe del Ministerio para la Transición Ecológica sobre la evaluación de la aplicación de la ley, de junio de 2020 (p. 27), disponible en su sitio web (https://www.miteco.gob. es/es/calidad-y-evaluacion-ambiental/temas/responsabilidad-mediambiental/informecama_030620_final_tcm30-509910.pdf), entre 2007 y 2019 tan solo se han tramitado $4^{2}$ procedimientos con arreglo a esta ley. Véase, también, al respecto, José Miguel Beltrán Castellanos, "De la transición ecológica a la responsabilidad medioambiental", en Observatorio de Políticas Ambientales 20rg, coord. por Fernando López Ramón (Madrid: Ciemat, 20rg), 540 y ss. 
En ocasiones, las medidas provisionales adoptadas en esta clase de procedimientos son objeto de impugnación en vía contencioso-administrativa ${ }^{91}$. Lo que con motivo de este tipo de asuntos ha venido a confirmar la jurisprudencia son las exigencias de proporcionalidad y motivación, que tienen reflejo hoy en la nueva regulación de la materia por la Ley 39/2015, y la excepcionalidad de la adopción de estas medidas inaudita parte, que, aunque no lo tiene, se deduce de los principios generales de la ley ${ }^{92}$.

A título de ejemplo en un caso reciente que ha alcanzado relevancia pública, como es el del derrumbe del vertedero vasco de Zaldíbar, la Administración competente (el Gobierno vasco) tomó todo un abanico de medidas provisionales con carácter previo a la iniciación del procedimiento de responsabilidad medioambiental o sancionador encargado de depurar las eventuales responsabilidades por daños ambientales, semejantes a las que adoptan los Tribunales Ambientales chilenos, incluyendo también medidas de evitación de daños mayores $^{93}$.

\section{CONCLUSIONES}

De manera sucinta, cabe esbozar las siguientes conclusiones del trabajo comparativo emprendido.

En primer lugar, no existen a mi modo de ver grandes diferencias de fondo entre los sistemas chileno y español de adopción de medidas cautelares en materia ambiental, como corresponde a una institución que desempeña funciones y presenta características comunes a escala universal, y a dos sistemas que mantienen en este campo una aproximación

91 Como actos de trámite cualificados, en la medida en que puedan causar "perjuicio irreparable a derechos o intereses legítimos” (artículo 25.I de la Ley 29/r998). En este sentido también, Tardío Pato, "Medidas provisionales”. En cambio, Toledo Martín, "Las medidas...", 300 y ss., las considera actos definitivos, y en tal condición susceptibles siempre de recurso contencioso-administrativo.

92 Así, por ejemplo, la sentencia del Tribunal Supremo del 20 de marzo de 2012 (recurso I5०I/2008), sobre una medida provisional de clausura total de una instalación de tratamiento de residuos, anulada por tomarse indebidamente inaudita parte y por vulneración del principio de proporcionalidad.

93 Orden del I3 de febrero de 2020, del Consejero de Medio Ambiente, Planificación Territorial y Vivienda, por la que se acuerda la adopción de medidas urgentes en relación al deslizamiento ocurrido en el vertedero de residuos no peligrosos ubicado en el término municipal de Zaldíbar (Vizcaya); mencionada en el posterior Decreto 35/2020, del 3 de marzo, por el que se aprueba la ejecución urgente de los depósitos de seguridad de residuos en el entorno del vertedero sito en el término municipal de Zaldibar (Boletín Oficial del País Vasco núm. 53, del ı6 de marzo). 
casuística, basada en la apreciación de la concurrencia o no de los requisitos tradicionales - aunque con desigual acento en el fumus boni iuirs - en cada caso concreto, sin recurrir a soluciones automáticas, quizás presentes en otros sistemas ${ }^{94}$.

Las diferencias son, pues, más bien de carácter adjetivo, derivadas de las equivalencias expuestas a lo largo del trabajo entre los asuntos siempre judiciales en el caso chileno y en parte administrativizados en el caso español.

En relación con la primera clase de asuntos, las reclamaciones de ilegalidad, contrasta la todavía escasa experiencia chilena con la abundantísima y variada experiencia contencioso-administrativa española en asuntos similares. De todas formas, algunos de los problemas que se plantean en España son ajenos al caso chileno, debido a la menor duración de los procesos tramitados por los Tribunales Ambientales.

En contraste, la experiencia cautelar chilena en las demandas de reparación por daño ambiental es ya considerable y valiosa, como lo será sin duda también la experiencia española en los procedimientos administrativos equivalentes, aunque su menor visibilidad impide en un trabajo de las modestas características del presente trazar comparaciones más precisas.

Por último, aunque esta conclusión excede del objeto del trabajo, debo reconocer que el conocimiento de la experiencia de los Tribunales Ambientales chilenos me ha servido para empezar a valorar una idea que puede servir para potenciar la efectividad del por lo demás espléndido nuevo régimen español de la responsabilidad medioambiental. Aunque la propia normativa comunitaria europea de la que trae causa exige que la responsabilidad medioambiental se depure en primera instancia en vía administrativa y no judicial, el establecer un recurso administrativo, previo al contencioso, ante órganos especializados e independientes, como los que empieza a haber en España en otras materias (contratos públicos, transparencia, etcétera), es decir, ante "tribunales (administrativos) ambientales”, en sustitución de los recursos ordinarios, podría ser quizás el revulsivo que necesita una legislación hasta ahora un tanto adormecida, pero de indudables bondades intrínsecas. $\square$

94 El sistema aplicado por los tribunales ambientales suecos, al que hace referencia entre nosotros Salazar Ortuño, El acceso..., 248. 


\section{AGRADECIMIENTOS}

Este pequeño trabajo trae causa de la amable invitación que recibí del Tercer Tribunal Ambiental de Chile, con sede en Valdivia, para impartir una charla sobre la justicia cautelar española en temas ambientales. Quiero expresar mi agradecimiento en particular al ministro Jorge Roberto Retamal Valenzuela, verdadero artífice de esta intervención, que tuvo lugar por videoconferencia el 15 de julio de 2020. 


\section{BIBLIOGRAFÍA}

- Beltrán Castellanos, José Miguel. Instrumentos para la efectividad del régimen de la responsabilidad medioambiental. Cizur Menor: Thomson Reuters Aranzadi, 2018.

- - "De la transición ecológica a la responsabilidad medioambiental". En Observatorio de Políticas Ambientales 2019, coordinado por Fernando López Ramón. Madrid: Ciemat, 2019.

- Blasco Hedo, Eva. "Suspensión provisional de la actividad cinegética por la estimación judicial de una medida cautelar versus modificación de la ley de caza de Castilla y León que autoriza su ejercicio". Actualidad Jurídica Ambiental 89 (2019): 47-61. https://dialnet.unirioja.es/ servlet/articulo? codigo $=6942929$.

- Casares Marcos, Anabelén. "Eficacia de las medidas cautelares en lo contencioso-administrativo". En 20 años de la Ley de lo contencioso-administrativo, coordinado por Fernando López Ramón y Julián Valero Torrijos. Madrid: Instituto Nacional de Administración Pública, 2019.

- Chinchilla Marín, Carmen. "El derecho a la tutela cautelar como garantía de la efectividad de las resoluciones judiciales". Revista de Administración Pública 131 (1993):165-190. https://dialnet.unirioja.es/ servlet/articulo? codigo $=17176$.

- Femenías Salas, Jorge Andrés. "El régimen general de responsabilidad por daño ambiental en la Ley 19.300 sobre bases generales del medio ambiente". Tesis doctoral de Universidad de Valladolid, 2015.

- - La responsabilidad por daño ambiental. Santiago: Universidad Católica de Chile, 2017.

- Gallego Bernard, María Soledad. La red Natura 2000 en España: Régimen jurídico y análisis jurisprudencial. Madrid: SEO/BirdLife, 2014.

- García de Enterría, Eduardo. La batalla por las medidas cautelares. Madrid: Civitas, 1992.

- - "Observaciones sobre la tutela cautelar en la nueva Ley de la Jurisdicción Contencioso-administrativa de 1998”. Revista de Administración Pública 151 (enero-abril 2000): 251-277. https://recyt.fecyt.es/ index.php/RAP/article/view/46231. 
- Gimeno Sendra, José Vicente. Fundamentos del derecho procesal. Madrid: Civitas, 1981.

- Jordano Fraga, Jesús. "El proceso de afirmación del medio ambiente como interés público prevalente o la tutela cautelar ambiental efectiva: La suspensión de los actos administrativos por razón de la protección del medio ambiente en la jurisprudencia del TS”. Revista de Administración Pública 145 (1998): 169-198. http://www.cepc.gob. es/publicaciones/revistas/revistaselectronicas?IDR=1\&IDN=143\&I$\mathrm{DA}=24159$.

- Marina Jalvo, Belén. Medidas provisionales en la actividad administrativa. Valladolid: Lex Nova, 2007.

- - "Las medidas provisionales administrativas: Novedades incorporadas por el artículo 56 de la Ley 39/2015, de 1 de octubre, de Procedimiento Administrativo Común de las Administraciones Públicas". Revista Vasca de Administración Pública 109, n. ${ }^{\circ} 1$ (2017): 163-188. https://dialnet.unirioja.es/servlet/articulo? codigo $=6251074$.

- Pring, George y Catherine Pring. Environmental Courts \& Tribunals: A Guide for Policy Makers. Nairobi: United Nations Environment Programme, 2016.

- Retamal Valenzuela, Jorge Roberto. "El ius imperium de los tribunales ambientales en Chile”. Revista Derecho del Estado 44 (2019): 257-284. doi: 10.18601/01229893.n44.10.

- Rodríguez de Santiago, José María. "El artículo 24.1 CE como 'norma de conducta' para jueces y tribunales y 'norma de control' para el Tribunal Constitucional". Revista Española de Derecho Constitucional 74 (2005): 261-277. http://www.cepc.gob.es/publicaciones/revistas/ revistaselectronicas?IDR=6\&IDN=596\&IDA $=26104$.

- Salazar Ortuño, Eduardo. El acceso a la justicia ambiental a partir del Convenio de Aarhus. Cizur Menor: Thomson Reuters Aranzadi, 2019.

- Tardío Pato, José Antonio. “Medidas provisionales”. En El procedimiento administrativo común (comentarios, jurisprudencia, formularios). Volumen 2. Coordinado por José Garberí Llobregat. Valencia: Tirant lo Blanch, 2007.

- Toledo Martín, Andrea. "Las medidas provisionales en el derecho alimentario". Tesis doctoral, Universidad de Navarra, 2012. 
- - Las medidas provisionales en el derecho alimentario y la responsabilidad patrimonial de la Administración por su adopción. Cizur Menor: Thomson Reuters Aranzadi, 2013.

- Valencia Martín, Germán. "La responsabilidad medioambiental". Revista General de Derecho Administrativo 25 (2010).

- - Jurisprudencia constitucional y medio ambiente. Cizur Menor: Thomson Reuters Aranzadi, 2017.

- - "Silencio administrativo común y especial". Revista Aragonesa de Administración Pública 53 (2019): 14-89. https://dialnet.unirioja.es/ servlet/articulo? codigo $=7041303$.

- - "Transformaciones urbanísticas en la red Natura 2000: El caso Valdecañas". Revista Aranzadi de Derecho Ambiental 45 (2020): 177-196.

- Valenzuela Silva, Elena Isabel. "La tutela cautelar ante los tribunales ambientales”. Memoria para optar al grado de Licenciado en Ciencias Jurídicas y Sociales, Universidad de Chile, Facultad de Ciencias Jurídicas y Sociales, 2019. 